\title{
Controlled trial of intravenous metronidazole as an adjunct to corticosteroids in severe ulcerative colitis
}

\author{
R W CHAPMAN, W S SELBY, AND D P JEWELL \\ From the Department of Gastroenterology, John Radcliffe Hospital, Headington, Oxford
}

SUMMARY A prospective double blind controlled trial was undertaken to examine the role of metronidazole as an adjunct to corticosteroids in the management of severe ulcerative colitis. Thirty nine patients with severe ulcerative colitis were randomised on admission to hospital to receive either intravenous metronidazole $500 \mathrm{mg}$ eight hourly (19 patients) or an identical intravenous placebo (20 patients). The two groups were similar with respect to age, sex, and the extent of colitis. In addition all patients received a standard intravenous regimen consisting of methyl prednisolone $16 \mathrm{mg}$ six hourly and parenteral nutrition together with a twice daily hydrocortisone $100 \mathrm{mg}$ enema. Treatment was continued for five days when the patients were formally assessed. Fourteen of 19 patients (74\%) receiving metronidazole and 14/20 (70\%) receiving placebo were substantially improved, or in remission at the end of five days. Five patients treated with metronidazole and six with placebo had no improvement and all proceeded to urgent colectomy with no operative mortality. There were three late deaths, one in the metronidazole and two in the placebo group. These results do not support the routine use of intravenous metronidazole in the treatment of severe ulcerative colitis.

The role of corticosteroids in the treatment of severe ulcerative colitis is well established. ${ }^{1}$ It is unclear, however, whether the addition of antibiotics increase the number of patients going into remission. In Oxford, tetracycline ${ }^{2}$ and more recently, intravenous metronidazole ${ }^{3}$ have been advocated as part of a five day treatment regimen which includes intravenous corticosteroids. Approximately two thirds of patients with severe ulcerative colitis will improve on this regimen. Controlled trials of antibiotics in severe ulcerative colitis, apart from those involving sulphasalazine ${ }^{45}$ have been limited to a recent study of vancomycin. ${ }^{6}$

In addition to its antimicrobial action, metronidazole has an immunosuppressive effect which may be of potential benefit in active colitis. ${ }^{7}$ Indeed, metronidazole has been shown to be beneficial in acute exacerbations of Crohn's disease, ${ }^{8}$ although its mechanism of action in Crohn's disease is not clear. ${ }^{8}$

The purpose of this study was to determine by means of a double blind controlled trial whether metronidazole is beneficial as an adjunct to in-

Address for correspondence: Dr R W Chapman, Senior Registrar, Department of Gastroenterology, John Radcliffe Hospital, Oxford.

Received for publication 6 February 1986 travenous corticosteroid therapy in acute, severe, ulcerative colitis.

\section{Methods}

\section{PATIENTS}

Thirty nine consecutive adult patients admitted to the John Radcliffe Hospital, Oxford, with acute severe ulcerative colitis were entered into the study. All patients gave their informed clinical consent to enter the study. The diagnosis of ulcerative colitis was established by sigmoidoscopy and rectal histology. A barium enema was available for all patients with a relapse of established disease and was carried out in first attack cases when the acute disease had settled. The criteria for judging the attack of colitis to be severe were those of Truelove and Witts. ${ }^{1}$ All patients in the study were passing at least six bloody motions daily. In addition, every patient had one or more signs of severity, consisting of fever $\left(>37.5^{\circ} \mathrm{C}\right)$, tachycardia $(>100$ beats/minute), anaemia, (haemoglobin $<10 \mathrm{~g} / \mathrm{dl}$ ), raised ESR $(>30 \mathrm{~mm} / \mathrm{h})$, low serum albumin $(<35 \mathrm{~g} / \mathrm{dl})$.

Patients were randomised to receive either metronidazole $500 \mathrm{mg}$ iv three times daily or an identical intravenous placebo preparation for five days, 
according to a schedule held by the hospital pharmacy, and unknown to the attending physicians. All patients received nil by mouth for five days in addition to a standard intravenous regimen; the details of which have been published elsewhere. ${ }^{23}$ The regimen consisted of $16 \mathrm{mg}$ methyl prednisolone six hourly, $100 \mathrm{mg}$ hydrocortisone given as an enema twice daily and parenteral nutrition. Patients received $2000 \mathrm{Kcal}$ and $14 \mathrm{~g}$ nitrogen per day during the study. Transfusions of blood were given as required to maintain the haemoglobin above $10 \mathrm{~g} / \mathrm{dl}$.

On admission, sigmoidoscopy and rectal biopsy were done. In addition to routine haematological investigations and plain abdominal radiograph, blood and stool cultures were obtained. ${ }^{9}{ }^{10}$ Faecal samples were assayed for Clostridium difficile toxin.

Each patient was formally assessed by one of the investigators (DPJ;RC) after completing five days of therapy. Patients were classified as either improved or no change/worse. The criteria for improvement was based on the passage of three or less formed or forming stools daily, the absence of rectal bleeding and abšence of clinical signs of severity such as pyrexia and/or tachycardia. Absence of decisive improvement by the end of the five day intensive course was taken as an absolute indication for colectomy. Any deterioration in the patient's condition during the course was regarded as an indication for emergency colectomy before intravenous treatment was completed

The difference in remission rates between the metronidazole and placebo groups was compared using the $\chi^{2}$ test.

\section{Results}

CLINICAL DETAILS

The clinical details of the 39 patients admitted into the study are shown in Table 1 . Nineteen patients were randomly allocated to receive metronidazole while 20 received placebo. The two groups were similar with respect to age, sex, and the extent of the colitis. Four patients in the metronidazole group and

Table 1 Clinical details of patients groups

\begin{tabular}{lcl}
\hline & $\begin{array}{l}\text { Metronidazole } \\
n=19\end{array}$ & $\begin{array}{l}\text { Placebo } \\
n=20\end{array}$ \\
\hline Men & 9 & 10 \\
Women & 10 & 10 \\
Mean age (range) & $46 \cdot 0 \mathrm{yr}(18-72)$ & $40 \cdot 3 \mathrm{yr}(16-85)$ \\
Total colitis & 10 & 11 \\
First attack & 4 & 5 \\
\hline
\end{tabular}

Table 2 Results of therapy

\begin{tabular}{lcc}
\hline & Metronidazole & Placebo \\
\hline Remission & $14(74 \%)$ & $14(70 \%)$ \\
No change or worse & $5(26 \%)$ & $6(30 \%)$ \\
Total & $19(100 \%)$ & $20(100 \%)$ \\
\hline
\end{tabular}

five in the placebo were undergoing their first attack of colitis.

\section{SHORT TERM RESULTS}

There was no difference in outcome between the two patient groups (Table 2). Five patients receiving metronidazole and six receiving placebo came to emergency colectomy for severe continuous symptoms of disease. No patient developed toxic megacolon or had to be withdrawn for clinical deterioration within the five day period. There were no operative deaths. No complications attributable to metronidazole or placebo were encountered in any of the patients.

No patient was found to have $C$ difficile on stool culture, and $C$ difficile toxin was absent in all cases. Blood cultures were all negative.

\section{OVERALL OUTCOME}

Two elderly patients in the placebo group died after proctocolectomy. One woman aged 85 died of heart failure six weeks after operation and a man of 74 died of bronchopneumonia five weeks after operation.

A young man of 20 in the metronidazole group went into remission but relapsed within three months and developed severe thromboembolic problems related to his colitis from which he died.

All the patients in the trial were followed up after completion for a minimum of one year.

\section{Discussion}

The results of this study show that metronidazole is not useful as an adjunct to intravenous corticosteroids in the treatment of patients with severe ulcerative colitis. A previous uncontrolled study from this unit described 100 patients with severe ulcerative colitis. These patients were treated similarly to those in the present study, except that tetracycline was used instead of metronidazole. ${ }^{2}$ The percentage number of patients going into remission was $75 \%$, similar to both groups in this study. This suggests that tetracycline, like metronidazole, may have no role as an adjunct to corticosteroids in the management of ulcerative colitis.

There have been no previous controlled trials of antibiotic therapy in the treatment of ulcerative 
colitis, with the exception of sulphasalazine and a recent study involving vancomycin. In the latter study there was no significant difference in outcome between groups of patients treated with either vancomycin or placebo. There was a trend, however, towards the reduction of operative intervention in the vancomycin treated group. No such trend in favour of antimicrobial therapy was seen in the patients reported in this trial.

None of the patients with acute exacerbations of ulcerative colitis had either $C$ difficile or $C$ difficile enterotoxin present in their stools on admission to hospital. Some studies have suggested that $C$ difficile enterotoxin is found in as many as $60 \%$ of severe exacerbations of ulcerative colitis. ${ }^{11} 12$ The present findings, however, are in agreement with those of Dickinson et al, who could not find $C$ difficile organism or enterotoxin in any of their patients with severe acute ulcerative colitis. ${ }^{6}$ Similarly, Meyers et al could only demonstrate $C$ difficile enterotoxin in $9 \%$ of 44 patients with active colitis. ${ }^{1.3}$

In conclusion, the results of this study do not support the routine use of metronidazole as an adjunct to corticosteroids in the treatment of severe ulcerative colitis.

\section{References}

1 Truelove SC, Witts LJ. Cortisone in ulcerative colitis. Final report on a therapeutic trial. Br Med J 1955; 2: 1041-48.

2 Truelove SC, Jewell DP. Intensive intravenous regi- men for severe attacks of ulcerative colitis. Lancet 1974 ; i: $1067-70$.

3 Jewell DP. Diagnosis and medical treatment of ulcerative colitis. Br J Hosp Med 1982: 27: 456-62.

4 Truelove SC. Watkinson G. Draper G. Comparison of corticosteroid and sulphalsazine therapy in ulcerative colitis. Br Med J 1962; 2: 1708-11.

5 Dick AP, Grayson MJ, Carpenter RG, Petrie A. Controlled trial of sulphasalazine in the treatment of ulcerative colitis. Gut 1964; 5: 437-42.

6 Dickinson RJ, O'Connor HJ, Pinder I, Hamilton I, Johnson D, Axon ATR. Double blind controlled trial of oral vancomycin as adjunctive treatment in acute exacerbations of ulcerative colitis. Gut 1985; 26: 1380-4.

7 Grove GI, Mahmoud AAF, Warren KS. Suppression of cell mediated immunity by metronidazole. Int Arch Allergy Appl Immunol 1977; 54: 422-7.

8 Ursing B, Alm T. Barany F, et al. A comparative study of metronidazole and sulfasalazine for active Crohn's disease: the Cooperative Crohn's Disease Study in Sweden. II Result Gastroenterology 1982: 83: 550-62.

9 Hafiz S, Oakley CL. Clostridium difficile: isolation and characteristics. J Med Microbiol 1976; 9: 129-37.

10 George RH. A micromethod for detecting toxins in pseudomembranous colitis. J Clin Pathol 1979; 32: 3)3-4.

11 Lamont JT, Trinka Y. Therapeutic implications of Clostridium difficile toxin during relapse of chronic inflammatory bowel disease. Lancet 1980) 1: 381-3.

12 Bolton RP, Sheriff RJ, Read AE. Clostridium difficile associated diarrhoea: a role in inflammatory bowel disease. Lancet 1980; i: 383-4.

13 Meyers S, Mayer L, Bottone E, Desmond E, Janowitz MD. Occurrence of clostridium difficile toxin occurring during the course of inflammatory bowel disease. Gastroenterology 1981; 80: 687-700. 